\title{
Effect of oral administration of pig spinal cord hydrolysate on clinical and histopathological symptoms of experimental allergic encephalomyelitis in rats
}

\author{
Kaja Kasarełto ${ }^{1,2}$, Roman Gadamski ${ }^{3}$, Piotr Piotrowski ${ }^{3}$, Katarzyna Kurzepa ${ }^{4}$, Barbara Kwiatkowska-Patzer ${ }^{1}$, \\ Andrzej W. Lipkowski ${ }^{1}$ \\ ${ }^{1}$ Department of Neuropeptides, Mossakowski Medical Research Centre, Polish Academy of Sciences, Warsaw, ${ }^{2}$ Department of Experimen- \\ tal and Clinical Physiology, Laboratory of Centre for Preclinical Research, Medical University of Warsaw, ${ }^{3}$ Department of Clinical and \\ Experimental Neuropathology, Mossakowski Medical Research Centre, Polish Academy of Sciences, Warsaw, ${ }^{4}$ Industrial Chemistry \\ Research Institute, Warsaw, Poland
}

\begin{abstract}
Oral tolerance is the natural occurring phenomenon of a decreased immune response to previously fed antigens, which prevents induction of a response to dietary antigens. One of the mechanisms is deletion of $T$ lymphocytes reactive to the fed antigen. Knowing that phenomenon, it seems appropriate to engage this mechanism for treatment of autoimmune diseases. Multiple sclerosis (MS) is an autoimmunological disease which causes neurological impairment in humans. Autoreactive $T$ lymphocytes migrate through the open blood-brain barrier into the central nervous system (CNS), where they recognize myelin antigens as foreign, and induce an inflammatory response against the myelin sheath, which causes demyelination and even axonal loss. Experimental allergic encephalomyelitis (EAE), an animal model of MS, resembles the autoimmunological aspect of the disease. We used a broad spectrum of myelin antigens to induce EAE, and also to induce oral tolerance by giving myelin epitopes intragastrically to rats. The aim of our study was to evaluate whether pig spinal cord hydrolysate given intragastrically is able to evoke oral tolerance in rats with an animal model of MS - EAE. In our experiments we fed female Lewis rats with pig spinal cord hydrolysate at doses of 5, 20 and $100 \mathrm{mg}$ per $\mathrm{kg}$ of body weight. We observed diminished clinical symptoms of ongoing EAE in rats fed with all doses of pig spinal cord hydrolysate. In the histopathological study, intensity of the inflammatory process in spinal cord was similar in rats not fed with EAE and in rats fed with lower doses of pig spinal cord hydrolysate. In animals fed with the highest dose of pig spinal cord hydrolysate, intensification of the inflammatory response was observed. These results were confirmed by morphometric evaluations. We found that feeding animals with preparations containing myelin antigens can reduce EAE symptoms, which may indicate oral tolerance induction, but the obtained results also underline the importance of dose of the orally given antigens, because of the possibility of enhancement of the inflammatory process in the CNS.
\end{abstract}

Key words: multiple sclerosis, EAE, oral tolerance, myelin antigens. 


\section{Introduction}

Oral tolerance is the phenomenon where a decrease of the immune response to previously fed antigens is observed. This mechanism occurs naturally in our organisms, and is necessary as a means of protection against evoking the immune response to non-pathogenic dietary antigens, and those from natural symbiotic gut bacteria $[7,41]$. When the short peptide fragments of digested proteins are being absorbed in the intestines, mucosa resident dendritic cells (DC) probe the antigens. There are two mechanisms of oral tolerance induction, depending on the dose of fed antigen. When low doses of antigen are given orally, DC induce differentiation of naive T-cells into regulatory T-cells, producing anti-inflammatory cytokines. This is called active suppression. Feeding with a high dose of antigen results in incomplete costimulation of autoreactive T-cells by $D C$ and consequently anergy or clonal deletion of autoreactive lymphocytes $[4,44]$. It is now known that both mechanisms occur simultaneously. There is also a "bystander suppression" mechanism involved, when anti-inflammatory cytokines produced by regulatory $\mathrm{T}$ lymphocytes suppress neighboring cells $[31,40]$.

Based on knowledge of the mechanism of oral tolerance, it seems to be appropriate to involve this phenomenon to treat autoimmune diseases. Oral administration of antigens, which are known or believed to be immunogenic in a particular disease, should induce oral tolerance, and in consequence "desensitize" the immunological system of the patient to those antigens. Since multiple sclerosis (MS) is an autoimmune disease in which the immune response is directed against myelin antigens, the aim should be to restore immune tolerance for these epitopes $[9,35]$.

Multiple sclerosis is an autoimmunological disease, leading to neurodegeneration, which causes progressive physical impairment in a patient. It is diagnosed in so-called "young adults", people between 20 and 40 years old, but also it affects both older people and children. The etiology of the disease still remains unknown, but there are some hypotheses proposing the involvement of genetic, environmental and infectious agents $[28,33]$. The unknown etiology is the main reason for the difficulty in developing an effective MS treatment. Unlike the etiology, more is known about mechanisms involved in MS pathogene- sis. Incorrectly activated autoreactive T lymphocytes migrate through the open blood-brain barrier into the central nervous system (CNS), and recognize myelin peptides as foreign antigens, which results in induction of an inflammatory response directed against the myelin sheath. Ongoing chronic inflammation can also lead to damage of the axons and neurons [10,35]. Demyelination and axonal loss are the direct cause of the physical impairment in patients. The most common symptoms are connected with vision disorders, paresis and incontinence, but also mental disorders are observed, such as depression, which is related to progressing physical disability $[30,33]$.

Experimental allergic encephalomyelitis (EAE) is the most commonly used MS animal model. It resembles the mechanism involved in the disease pathogenesis. Animals are immunized with a mixture containing myelin antigens to direct the immune response to the myelin sheath in the CNS, and adjuvant to enhance the inflammation (active form of EAE). Animals may also be immunized by passive transfer of autoreactive T-lymphocytes (passive EAE). The most common sources of myelin epitopes in the immunization mixture are single myelin proteins or even fragments of them. Depending on the used epitope, the course and symptoms of induced EAE may differ $[2,23,43]$. Myelin oligodendrocyte glycoprotein (MOG) $35-55$ is considered to be the most encephalogenic myelin epitope, and EAE induced using this epitope is chronic, and characterized by inflammatory infiltrations in the CNS $[12,13]$. Unlike MOG-induced EAE, the one induced with myelin basic protein (MBP) or its fragments is acute, with no relapses and very rarely observed demyelination. In our experiments we used whole guinea pig spinal cord homogenate as a source of myelin antigens in the immunization mixture. There may be many immunogenic antigens in MS, so using a broad spectrum of myelin epitopes to induce EAE may more closely resemble the disease. In the cerebrospinal fluid (CSF) of the patients, antibodies not only against three main myelin proteins (MBP, MOG, and PLP - proteolipid protein) are found, but also against some other myelin components [14,35]. Experimental allergic encephalomyelitis induced with a mixture containing whole spinal cord homogenate was used in Dark Agouti rats, except for using rat instead of guinea pig spinal cord. The results showed that induced EAE has relapsing-remitting form, and also 
inflammatory infiltration and demyelination in the CNS were observed [3].

Most previous studies have concerned evoking oral tolerance to MBP in animals with MBP-induced EAE $[6,11,26]$, but using broad a spectrum of myelin antigens in the preparations given intragastrically to induce oral tolerance seems to be more accurate, since it is not known precisely which myelin antigens are responsible for MS pathogenesis. Hydrolyzed pig spinal cord provides all myelin antigens, which consequently may evoke oral tolerance to all possible immunogenic myelin epitopes.

There are a few common methods of MS treatment so far, but the efficiency is not satisfactory, or the side effects are very severe. General immunosuppression during disease relapse is obtained by the use of glucocorticosteroids [27,34]. Chronic immunomodulation is provided by interferon- $\beta$, which unfortunately after some period of use is neutralized by antibodies produced by the patient's body. Also efficacy is not observed in all patients [1] In recent years there have been some new therapies, which target specific mechanisms involved in MS pathogenesis, for example natalizumab, which inhibits migration of the autoreactive $T$ lymphocytes through the blood-brain barrier into the CNS, but carrying the risk of lethal progressive multifocal leukoencephalopathy (PML) occurrence [5]. Because of the lack of sufficiently effective MS therapy, there is a need to look for new treatment methods. Oral tolerance is very promising as a new MS therapy.

The aim of our study was to evaluate whether feeding of rats with pig spinal cord hydrolysate affects the clinical symptoms and histopathological changes in rats with $E A E$ - an animal model of MS.

\section{Material and methods \\ Animals}

In our experiments we used female Lewis rats, weighing 180-200 g at the beginning of the experiment. Experiments were carried out based on the consent of the Fourth Local Ethics Committee in Warsaw.

\section{Feeding}

Experimental animals were fed with a mixture $(0.5 \mathrm{ml})$ containing myelin peptides, with a ball-pointed needle. The source of myelin antigens was the pig spinal cord hydrolysate in doses of 5, 20, $100 \mathrm{mg} / \mathrm{kg}$ of body weight. Control animals were fed with a me- dium dose of pig spinal cord hydrolysate $(20 \mathrm{mg} /$ $\mathrm{kg}$ ). Hydrolysate was prepared by pig spinal cord digestion with pepsin, which resembles the natural process of protein digestion in the gastrointestinal tract. After digestion, a mixture of proteins, peptides, amino acids and lipids was obtained. Such a mixture was then rinsed with water, which allowed extraction of the fraction of amino acids and peptides, which were then rinsed with $70 \%$ ethanol. Three fractions were collected: amino acids, low molecular weight peptides and high molecular weight peptides. The fraction of low molecular weight, short peptides was used in our experiments [24]. Rats were fed four times during one week (every second day). Animals were deprived of food for two hours before feeding with preparations.

\section{Experimental allergic encephalomyelitis induction}

One week after the last day of feeding, the EAE was induced. Rats under inhaled anesthesia, 0.5-3.5\% Narcotan (Leciva a.s.) in oxygen, were injected intradermally into the hind paws with the immunizing mixture $(100 \mu \mathrm{l} / \mathrm{paw})$. The mixture contained $50 \%$ guinea pig spinal cord homogenate as a source of myelin antigens mixed in the ratio $1: 1$ with Freund Adjuvant (DIFCO LABORATORIES), and supplemented with $4 \mathrm{mg} / 1 \mathrm{ml}$ Mycobacterium tuberculosis (DIFCO LABORATORIES).

\section{Clinical evaluation}

During the experiment animals were weighed every day, and after EAE induction the clinical symptoms were evaluated using a 5 -grade scale $(1-\operatorname{limp}$ tail, 2 - hind leg weakness, 3 - paraplegia and incontinence, 4 - quadriplegia, 5 - death). At the $14^{\text {th }}$ day post immunization (14 DPI) rats were subjected to deep anesthesia with the intraperitoneal injection of $0.67 \mathrm{ml} / \mathrm{kg}$ ketamine and $0.5 \mathrm{ml} / \mathrm{kg}$ xylazine (Vetoquinol Biowet), and perfused transcardially with $4 \%$ paraformaldehyde. Lumbar and cervical segments of spinal cords were collected from the spinal canal of the vertebral column for further histopathological analysis.

Body mass index was calculated as the ratio of body mass at 14 DPI and at the day of evoking EAE (0 DPI, taken as 1). Mean clinical score was calculated as the mean of clinical scores between 11 and 14 DPI. 


\section{Histopathological studies}

Spinal cord fragments were embedded in paraffin, and cut into slices $(8 \mu \mathrm{m})$. Some of the slices were stained with a $1 \%$ water solution of cresyl violet to expose cells. Other slices were labeled with anti-T cells (Anti-CD45RO), anti-GFAP or anti-vimentin antibodies as follows. After blocking of endogenous peroxidase with $3 \%$ hydrogen peroxide in dewaxed slices, the background was blocked with $10 \%$ albumin. Next, slices were incubated with primary antibodies, washed, and incubated with a secondary antibody coupled with biotin. Streptavidin coupled with peroxidase was afterwards applied, and then chromogen was put on. All primary and secondary antibodies were supplied by DAKO. Subsequently slices were stained with Mayer's hematoxylin. Slices were analyzed using a light microscope.

\section{Morphometric studies}

Slices stained with cresyl violet were analyzed. Slices were photographed (3-35AD camera-4, Olympus), and images were scanned from photographic film. Whole spinal cord cross-section area and the area occupied with inflammatory infiltrations were measured using a computer program (GIMP 2.4.5). Percentage of both lumbar and cervical spinal cord segment sections occupied by inflammatory infiltrations was calculated as the ratio of the whole slice area to the area occupied by the inflammatory infiltration.

\section{Statistical analysis}

Results are shown as mean \pm SD. Statistical analysis was performed using the non-parametric Mann-Whitney statistical test. Results were statistically significant when $p<0.05$.

\section{Results}

Animals fed with all three doses of pig spinal cord hydrolysate (EAE + Hy5, EAE + Hy20, EAE + Hy100) showed a substantial decrease of the clinical score in comparison to non-fed EAE rats (EAE). Figure 1 shows the mean clinical score observed between 11 and 14 DPI. Experimental allergic encephalomyelitis induction decreases the body mass in comparison to not-treated animals (NT) (Fig. 2). Feeding rats with three doses of pig spinal cord hydrolysate (EAE + Hy5, EAE + Hy20, EAE + Hy100) does not reverse the observed body mass drop after EAE induction. Feeding healthy animals with pig spinal cord hydrolysate (Hy) causes no changes in body mass in comparison to non-treated animals (NT).

Slices from collected spinal cord segments from EAE rats underwent histopathological and morphometric evaluation. Cresyl violet staining revealed cross-sectional spinal cord structure differentiated into white and gray matter. Motoneurons were seen in the anterior horns of gray matter (Fig. 3A). After evoking EAE we observed numerous perivascular inflammatory infiltrations in both white and gray matter, and also at the border between the two matters (Fig. 3B). Inflammatory infiltrates showed perivascular location (Fig. 3C). The inflammatory process

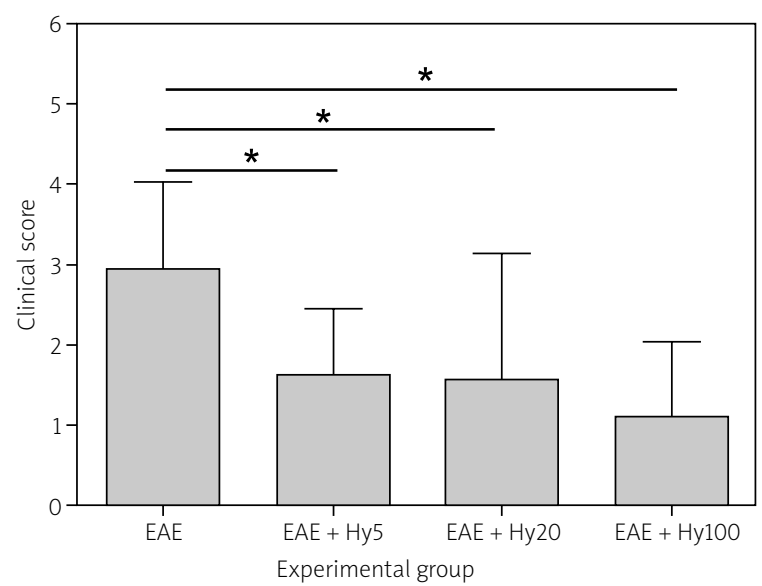

Fig. 1. Mean clinical score between 11 and $14 \mathrm{DPI}$. $n=5-13 ;{ }^{*} p \leq 0.05$.

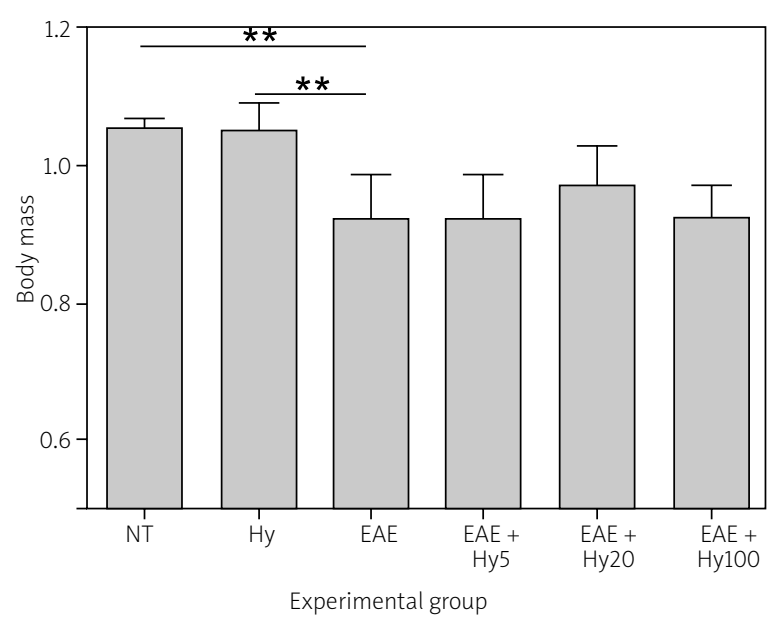

Fig. 2. Body mass at $14 \mathrm{DPI}$ in relation to $0 \mathrm{DPI}$ (taken as 1). $n=5-13 ;{ }^{*} p \leq 0.05 ;{ }^{* *} p \leq 0.01$. 

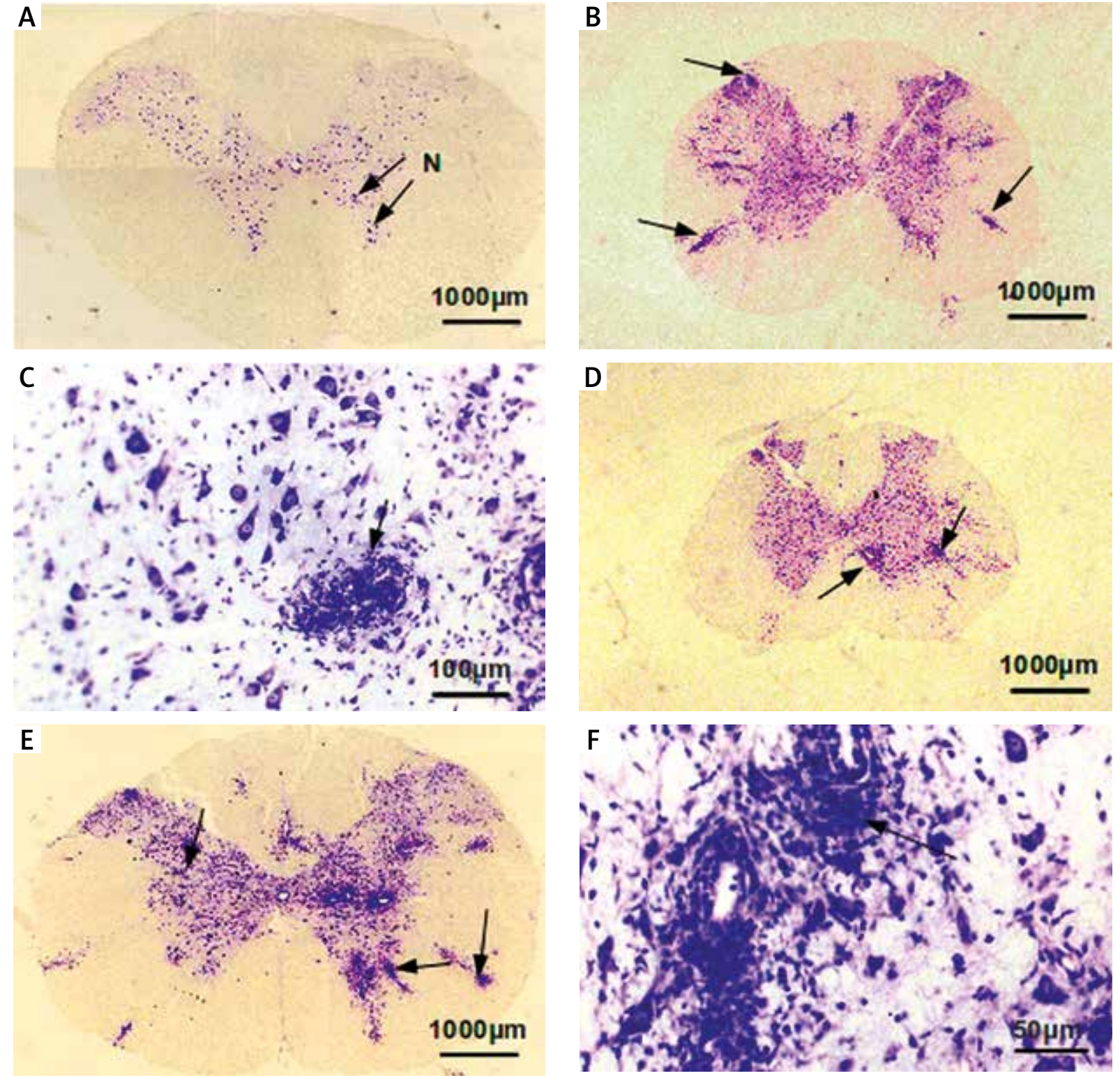

Fig. 3. Morphological changes. Spinal cord cross-section. Cresyl violet staining (KV). A) Motoneurons in the anterior horns, non-treated animals. B, C) Perivascular inflammatory infiltrations in white and gray matter, non-fed, EAE animals. D) Inflammatory infiltrations, EAE animals, fed with hydrolysate in doses 5 and $20 \mathrm{mg} / \mathrm{kg}$. E, F) Inflammatory infiltrations, EAE animals, fed with hydrolysate in dose $100 \mathrm{mg} / \mathrm{kg}$. Inflammatory infiltrations marked by arrows. $\mathrm{N}$ - motoneuron.

in the animals fed with lower doses of pig spinal cord hydrolysate, 5 and $20 \mathrm{mg} / \mathrm{kg}$, showed similar intensity as in non-fed EAE rats (Fig. 3D). In contrast, in animals fed with the highest dose of pig spinal cord hydrolysate, $100 \mathrm{mg} / \mathrm{kg}$, higher inflammatory activity was observed. There were more perivascular infiltrates present (Fig. 3E), and they were more abundant in inflammatory cells (Fig. 3F).
Anti-T cell labeling showed the presence of $T$ lymphocytes in inflammatory infiltrates. Immunoreaction is visualized as a red tint in the cytoplasm of cells (Fig. 4A) and in neuropil (Fig. 4B).

Anti-GFAP labeling showed reactive astrocytes present in the cross-section of the spinal cord. In nontreated animals there was limited reaction revealing astrocyte processes in white matter (Fig. 5A). 

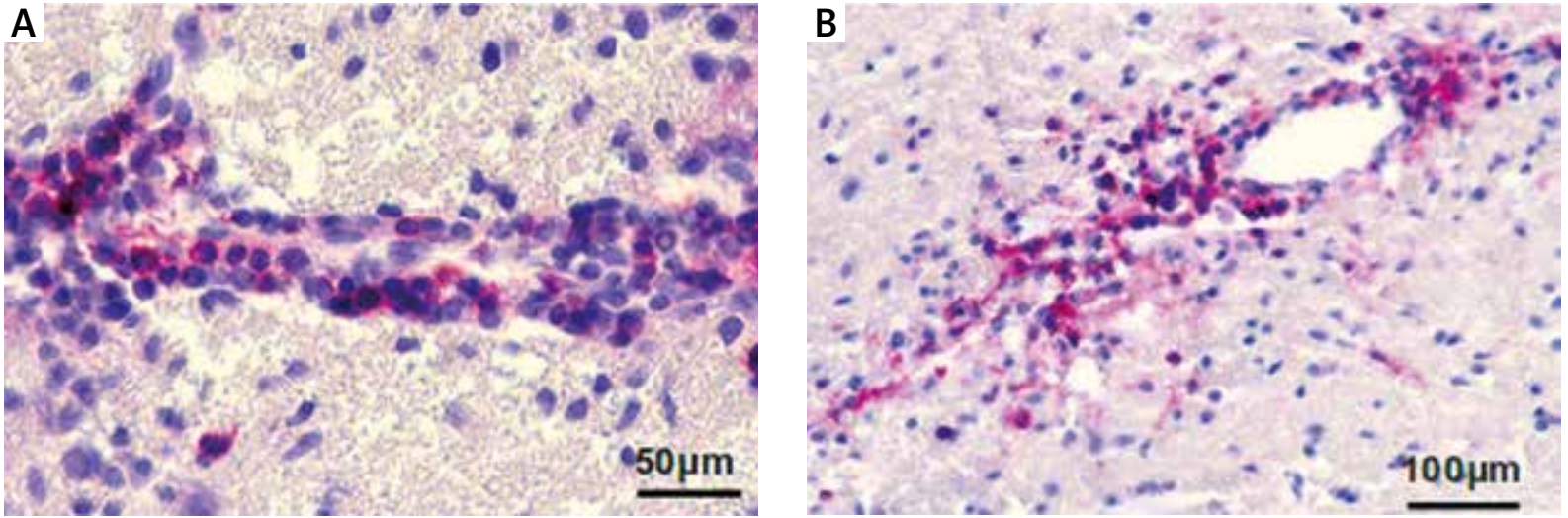

Fig. 4. T lymphocytes in inflammatory infiltrates. Spinal cord cross-section. Anti-T lymphocyte labeling.
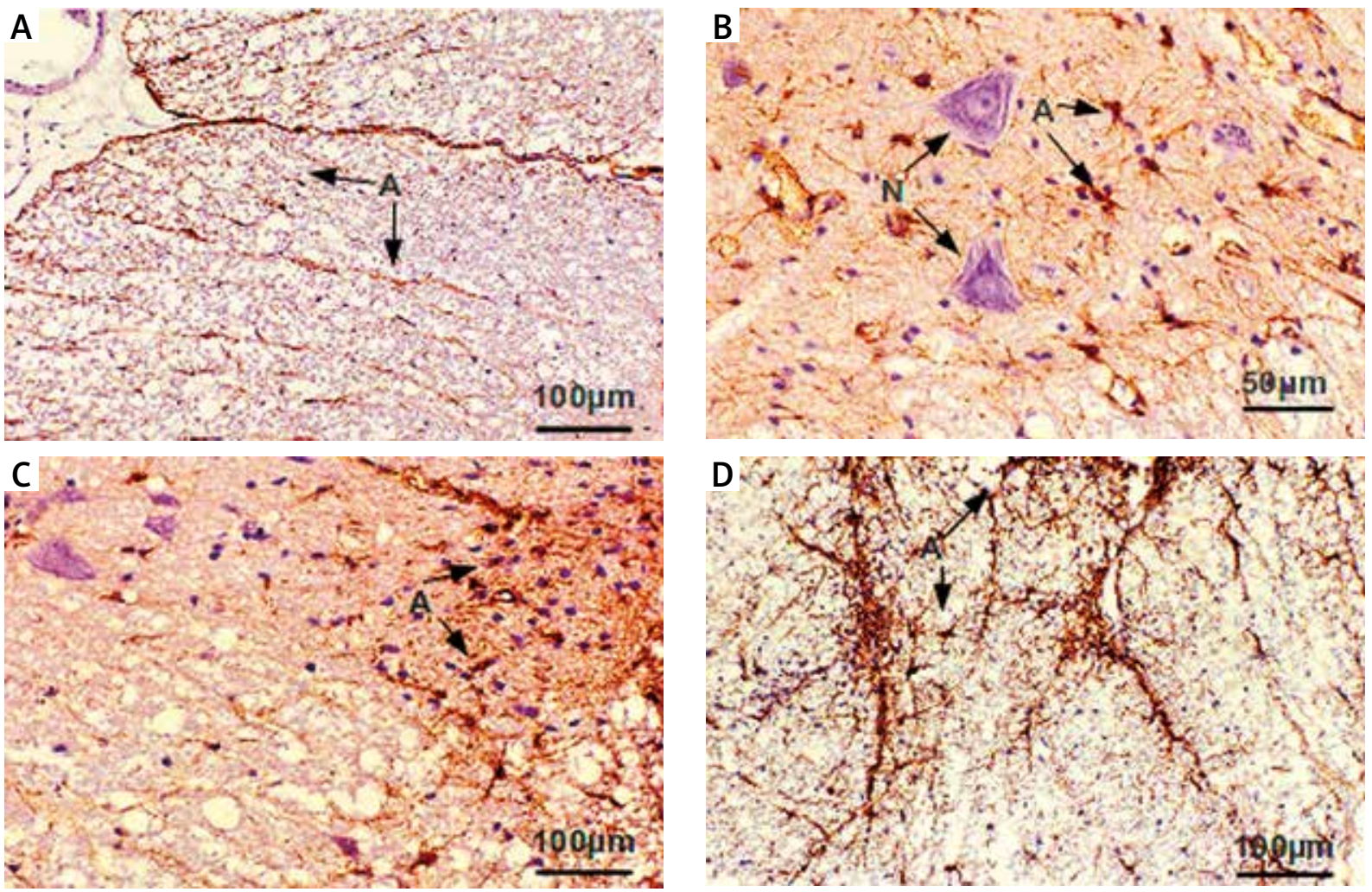

Fig. 5. Astrocytic reaction. Spinal cord cross-section. Anti-GFAP labelling. A) Scant astrocytic reaction in the white matter, non-treated animals. B, C) Increased number of astrocytes, EAE animals, fed with hydrolysate in doses 5, $20 \mathrm{mg} / \mathrm{kg}$. D) Intensive astrocytes immunoreactivity, EAE animals, fed with hydrolysate in dose $100 \mathrm{mg} / \mathrm{kg}$. Astrocytes marked by arrows. $\mathrm{N}$ - motoneuron.

A slightly increased number of astrocytes and increase in immunoexpression apparent in astrocyte cytoplasm and processes was observed after EAE induction (Fig. 5B) and in rats fed with both lower doses, 5 and $20 \mathrm{mg} / \mathrm{kg}$, of pig spinal cord hydrolysate (Fig. 5C). Astrocyte immunoreactivity in cross-sections of spinal cords from rats fed with pig spinal cord hydrolysate in a dose of $100 \mathrm{mg} / \mathrm{kg}$ was enhanced (Fig. 5D) in comparison to that observed in rats fed with lower doses of hydrolysate.

Anti-vimentin immunoreactivity in the spinal cord sections was similar to GFAP immunoreaction. Limited reaction was observed in sections from non-treated animals (Fig. 6A). Enhanced reac- 

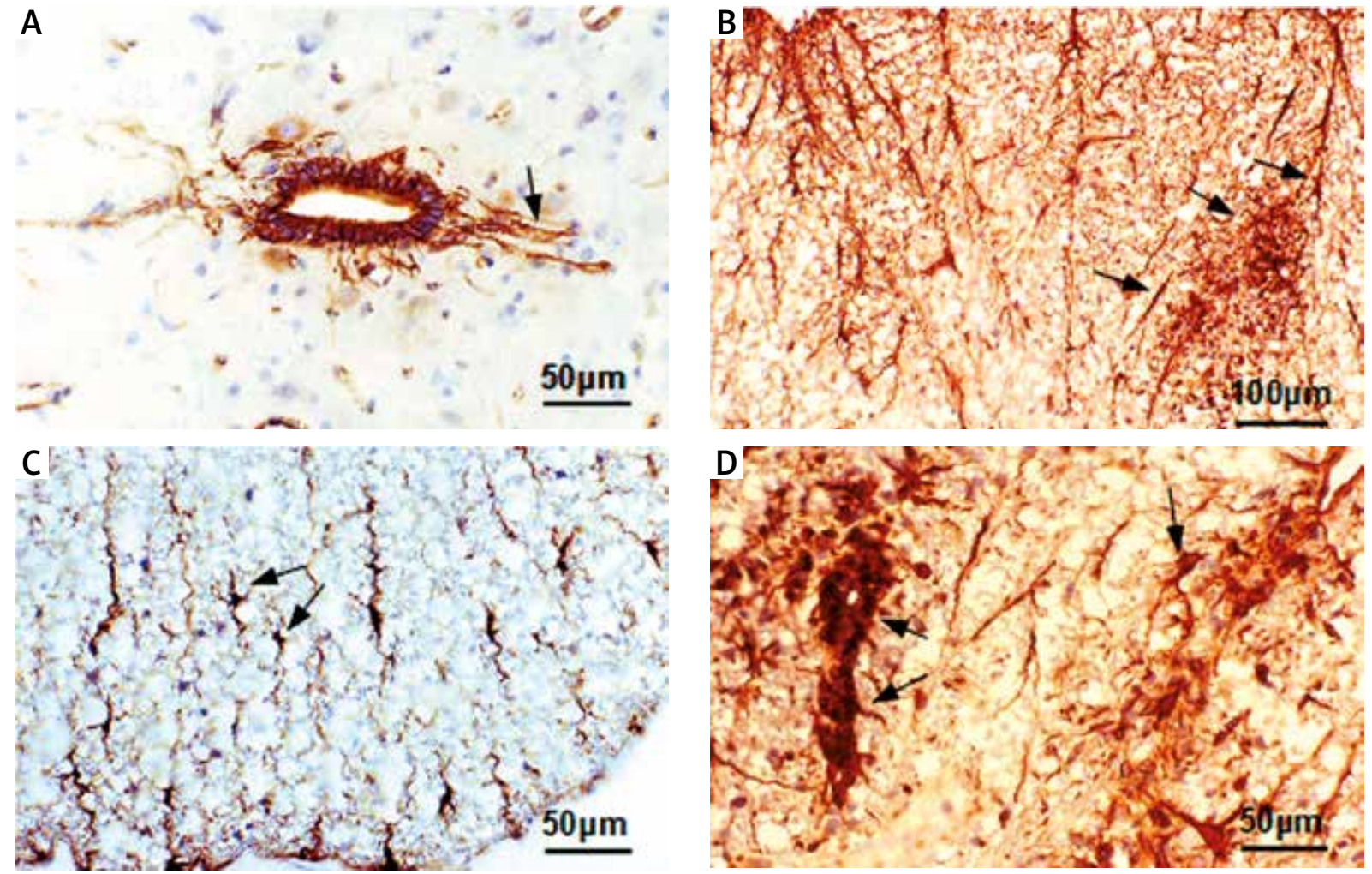

Fig. 6. Astrocytic reaction. Spinal cord cross-section. Anti-Vimentine labelling. A) Scant astrocytic reaction, non-treated animals. B, C) Enhanced astrocytic reaction, EAE animals, fed with hydrolysate in doses 5, $20 \mathrm{mg} / \mathrm{kg}$. D) Enhancement of vimentine expression, EAE animals, fed with hydrolysate in dose $100 \mathrm{mg} / \mathrm{kg}$. Astrocytes marked by arrows.
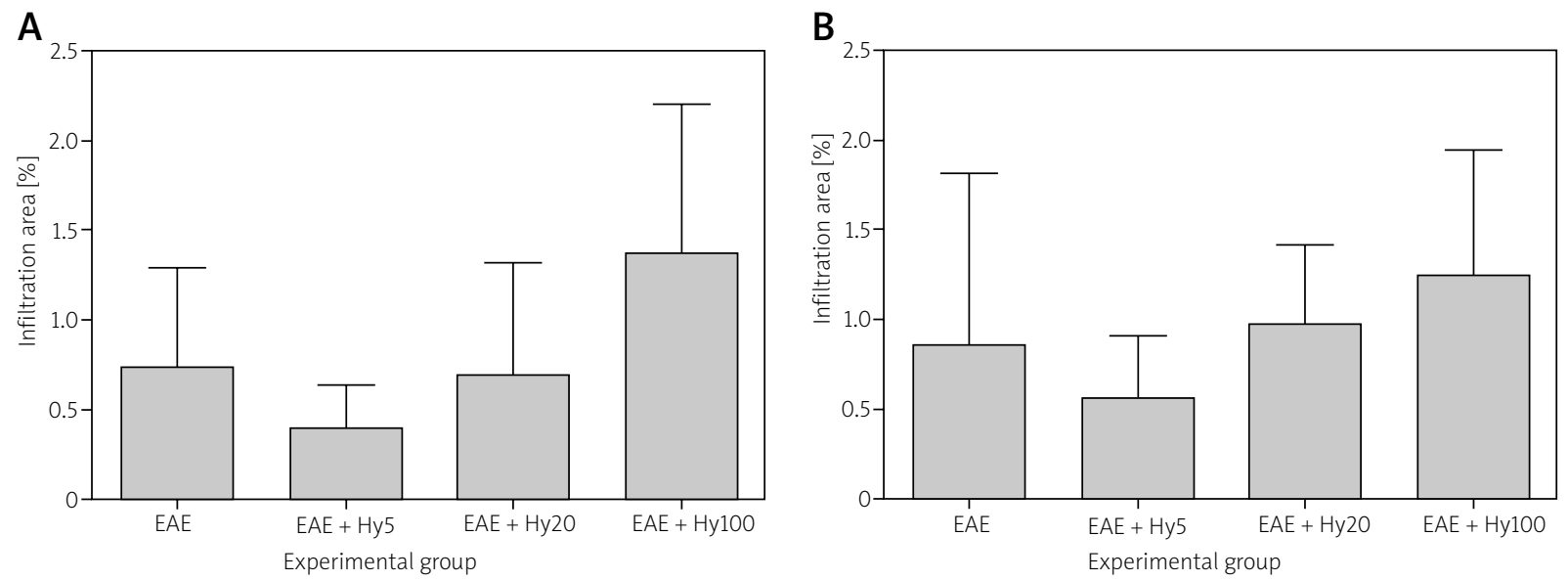

Fig. 7. Percentage of section area occupied by inflammation infiltrations. A) Cervical segment of spinal cord. B) Lumbar segment of spinal cord. $n=5-13$.

tion was observed in the sections from animals with induced EAE (Fig. 6B) and in the slices of spinal cord from animals fed with lower doses, 5 and $20 \mathrm{mg} / \mathrm{kg}$, of pig spinal cord hydrolysate (Fig. 6C). As in anti-GFAP labeling, there was enhancement in immunoexpression seen in astrocytes shown in slices obtained from rats fed with $100 \mathrm{mg} / \mathrm{kg}$ pig spinal cord hydrolysate (Fig. 6D).

Morphometric analysis confirmed histopathological evaluations indicating similar inflammatory 
activity observed in cross-sections of spinal cords from rats fed with $20 \mathrm{mg} / \mathrm{kg}$ of pig spinal cord hydrolysate, and the enhancement of inflammatory activity in spinal cords of rats fed with the highest dose, $100 \mathrm{mg} / \mathrm{kg}$ of hydrolysate, in comparison to non-fed EAE rats. Figure 7 presents morphometric studies in cervical (Fig. 7A) and lumbar (Fig. 7B) segments of spinal cords. We can observe similar dependencies in both spinal cord segments. Feeding animals with the lowest dose, $5 \mathrm{mg} / \mathrm{kg}$, of pig spinal cord hydrolysate showed a tendency to decrease the area occupied by inflammatory infiltrations in comparison to non-fed EAE rats, whereas the highest dose, $100 \mathrm{mg} /$ $\mathrm{kg}$, had the opposite effect - we observed a tendency to increase the area occupied by inflammatory infiltrations. Feeding rats with a dose of $20 \mathrm{mg} / \mathrm{kg}$ shows a similar ratio of inflammatory infiltration areas in spinal cord sections as non-fed EAE rats.

\section{Discussion}

Multiple sclerosis is a disease known for almost two centuries, but still there is no proper and effective method of its treatment. Looking for new therapies is difficult because of not knowing the disease etiology. Each applied way of MS treatment is based on the disease mechanism, and since it is an autoimmune disorder, the most popular methods are based on suppression or modulation of immune system activity. Such a procedure is able to diminish the clinical symptoms of the disease, but at the same time it exposes the patient to infections [32]. That leads us to look for another MS therapy. In our opinion, reinstatement of immune tolerance for myelin autoantigens should be taken into account when looking for a new method of MS treatment. That can be provided by the oral tolerance phenomenon, as a mechanism that reduces the immune response to a previously fed antigen $[39,41]$. The first reports about involvement of oral tolerance in the treatment of the MS animal model, experimental allergic encephalomyelitis, came from 30 years ago. The best studied myelin protein is myelin basic protein, and its immunogenic properties are well known [37]. Most experiments were conducted using MBP as a source of myelin antigens in both the immunizing mixture and the orally given preparations. Orally given MBP protected rats from progression of subsequently induced MBP-EAE, reduced the anti-MBP antibody level in serum [22], and also inhibited clinical and histopathological symptoms of EAE [17].

In our experiments we induced EAE with a mixture containing whole guinea pig spinal cord homogenate as a source of myelin antigens. We found it more appropriate, since it is not known which particular antigen is immunogenic in MS pathogenesis, and antibodies against many myelin epitopes are found in CSF of the patients [14]. If as seems likely there are many immunogenic myelin antigens in the MS pathogenesis, it will also be more appropriate to restore immune tolerance for all those epitopes. In our experiments we used whole pig spinal cord hydrolysate as a source of all potential immunogenic myelin antigens in the orally given preparations. The approach where more than one myelin antigen was used was applied in studies in relapsing-remitting MS patients. Peptide fragments of three main myelin proteins, MBP, PLP and MOG, were given to patients transdermally, using patches stuck to the skin of the arm. There was a reduction in the number of lesions visible in MRI imaging and the annual relapse rate in patients treated transdermally with myelin antigens in comparison to the placebo group $[15,38]$.

In our experiments we observed diminished clinical symptoms of induced EAE in rats previously fed with all three doses of pig spinal cord hydrolysate. The mean score was reduced by about $50 \%$ in comparison to the mean score in non-fed EAE rats. This result may indicate oral tolerance induction. We did not observe a reduction in body mass drop caused by EAE induction in rats fed with pig spinal cord hydrolysate. Nevertheless, this is a parameter reflecting the general condition of animals, and is not directly associated with induction of oral tolerance. No differences observed in body mass between non-treated rats and those that received pig spinal cord hydrolysate without EAE induction may indicate safety of using such preparations. Still, toxicology studies should be conducted to define the safeness of pig spinal cord hydrolysate. There are no known toxic prion proteins identified in swine which could exclude pig CNS tissue from usage in clinical trials [18].

Published data show that in rats immunized with a mixture containing syngeneic spinal cord as a source of myelin antigens in the acute phase of EAE (14 days after immunization) infiltration of immune cells into the lumbar spinal cord occurred [8]. In the spinal cord sections from animals used in our experiments, at the 14th day after immuni- 
zation we observed infiltration of immune cells into the CNS.

Histopathological evaluations of spinal cord slices showed that lower doses of pig spinal cord hydrolysate given to rats intragastrically have no influence on the extent of the inflammatory process in the CNS of the EAE rats. A similar intensity in perivascular inflammatory infiltrations and astrocyte activity in fed and non-fed EAE rats was observed. Surprisingly, despite the decreased mean clinical score in rats fed with the highest hydrolysate dose, $100 \mathrm{mg} / \mathrm{kg}$, the inflammatory process was intensified in comparison to non-fed EAE rats. It was pronounced as more numerous and abundant in immune cell infiltrations. Also higher astrocyte activity was observed. These evaluations were confirmed by the morphometric analysis. The results can be considered only as a tendency, because of strong diversity of the experimental groups, which causes the lack of significance of the results. Nonetheless, quite clear associations were seen in morphometric analysis, very similar in both cervical and lumbar segments of spinal cords. In rats fed with a higher dose of hydrolysate, $100 \mathrm{mg} /$ $\mathrm{kg}$, there was a tendency to increase the area of slice occupied by inflammatory infiltrations, which is in accordance with observations of intensity of infiltration in spinal cord slices. Interestingly, although microscopic observations did not allow one to notice the differences, morphometric study showed a tendency to decrease the area of the rat spinal cord cross-section occupied by inflammatory infiltrations in rats fed with a lower dose of pig spinal cord hydrolysate $5 \mathrm{mg} / \mathrm{kg}$. Hydrolysate given in a dose of $20 \mathrm{mg} /$ kg showed no effect.

Based on the obtained results, we can conclude that the lowest dose of given intragastrically pig spinal cord hydrolysate mitigates the clinical symptoms of induced EAE in rats, which may indicate oral tolerance to myelin antigen induction. Results obtained from animals fed with the medium dose of hydrolysate showed diminished clinical symptoms in animals, but no influence on intensity of the inflammatory process in the CNS. We know that regulatory T-cells induced by oral tolerance may infiltrate the CNS, where they suppresses inflammation [42]. Evaluation of the phenotype of infiltrated T-cells might show whether infiltration consists partly of regulatory cells, which would indicate oral tolerance induction. Our pilot trials examining the cytokine levels showed increased IL-10 levels in brain and spinal cord homogenates in rats fed with pig spinal cord hydrolysate in a dose of $20 \mathrm{mg} / \mathrm{kg}$ [20]. Peron et al. [29] observed that mice with MOG35-55-induced $E A E$, and the same antigen given orally to induce oral tolerance, had a reduced amount of both Th17 and Th1 cells infiltrating into the CNS. Diminished perivascular infiltrations in the CNS were also observed in rats fed with MBP conjugated with the cholera toxin B subunit [36].

The results of our investigations underline the importance of antigen doses. We found that the highest dose of the pig spinal cord hydrolysate caused intensification of inflammatory processes in the CNS, marked not only by greater immune cell infiltration, but also increased astrocyte activity, which indicates enhancement of the autoaggressive process.

Previously we also found that feeding animals with pig spinal cord hydrolysate influences the changes, such as opened tight junctions, in bloodbrain barrier ultrastructure, after evoking EAE [19]. There was also a decreased concentration of metalloproteinases, which are responsible for rearrangements of extracellular matrix, which leads among other things to blood-brain barrier opening [21].

Clinical symptoms observed in animals reflect physical disability in patients suffering from MS, such as limb weakness and even paralysis, or incontinence $[21,23]$. Since we know that physical disability results from neurodegeneration, improvement in clinical symptoms should indicate a decrease in inflammatory process intensity. Also, oxidative stress plays a major role in tissue destruction. Reactive oxygen and nitrogen species (ROS, RNS) are excessively produced by activated immune cells. Myelin, being composed mainly of lipids and proteins, is very vulnerable to peroxidation, leading to function loss and damage [25]. It was shown that there is a temporal coincidence between myelin-specific T-cell CNS penetration and the first clinical symptoms of EAE occurrence [16]. This underlines the importance of sufficient infiltration prevention, or inactivation of already infiltrated immune cells in the CNS. In our experiments, administering hydrolysate in the dose of $5 \mathrm{mg} / \mathrm{kg}$ showed a tendency to diminish the area occupied by inflammatory infiltration.

The obtained results indicate that usage of preparations containing pig spinal cord hydrolysate, as a source of broad spectrum myelin antigens, is able to diminish clinical symptoms of ongoing EAE. The results also underline the very important aspect 
of the dose of fed antigens. Decreased clinical symptoms may indicate oral tolerance induction, but further, antigen-specific analysis should be conducted. Nevertheless, preparations containing pig spinal cord hydrolysate may be in the future very promising as a new method for multiple sclerosis treatment.

\section{Acknowledgements}

The study was supported by grant MNI 017/PO5/ 2005/29.

\section{Disclosure}

\section{Authors report no conflict of interest.}

\section{References}

1. Axtell RC, de Jong BA, Boniface $K$, van der Voort LF, Bhat R, De Sarno P, Naves R, Han M, Zhong F, Castellanos JG, Mair R, Christakos A, Kolkowitz I, Katz L, Killestein J, Polman CH, de Waal Malefyt R, SteinmanL, Raman C. T helper type 1 and 17 cells determine efficacy of IFN- $\beta$ in multiple sclerosis and experimental encephalomyelitis. Nat Med 2010; 16: 406-412.

2. Baker D, Jackson SJ. Models of multiple sclerosis. Adv Clin Neu rosc Rehabil 2007; 6: 10-12.

3. Beeton C, Garcia A, Chandy KG. Induction and clinical scoring of chronic-relapsing experimental autoimmune encephalomyelitis. J Vis Exp 2007; 5: 1-2.

4. Benson JM, Campbell KA, Guan Z, Gienapp IE, Stuckman SS, Forsthuber T, Whitacre CC. T-cell activation and receptor downmodulation precede deletion induced by mucosally administered antigen. J Clin Invest 2000; 106: 1031-1038.

5. Castro-Borrero W, Graves D, Frohman TC, Bates Flores A, Hardeman P, Logan D, Orchard M, Greenberg B, Frohman EM. Current and emerging therapies in multiple sclerosis: a systematic review. Ther Adv Neurol Disord 2012; 5: 205-220.

6. Faria AMC, Maron R, Ficker SM, Slavin AJ, Spahn T, Weiner HL. Oral tolerance induced by continuous feeding: enhanced up-regulation of transforming growth factor- $\beta$ /interleukin-10 and supression of experimental autoimmune encephalomyelitis. J Autoimmun 2003; 20: 135-145.

7. Faria AMC, Weiner HL. Oral tolerance: Therapeutic implications for autoimmune diseases. Clin Dev Immunol 2006; 13: 143-157.

8. Giatti S, Boraso M, Abbiati F, Ballarini E, Calabrese D, Santos-Galindo M, Rigolio R, Pesaresi M, Caruso D, Viviani B, Cavaletti G, Garcia-Segura LM, Melcangi RC. Multimodal analysis in acute and chronic experimental autoimmune encephalomyelitis. J Neuroimmune Pharmacol 2013; 8: 238-250.

9. Gravano DM, Vignali DAA. The battle against immunopathology: infectious tolerance mediated by regulatory T cells. Cell Mol Life Sci 2012; 69: 1997-2008.

10. Hellings N, Raus J, Stinissen P. Insights into the immunopathogenesis of multiple sclerosis. Immunol Res 2002; 25: 27-51.

11. Higgins PJ, Weiner HL. Supression of experimental autoimmune encephalomyelitis by oral administration of myelin basic protein and its fragments. J Immunol 1988; 140: 440-445.
12. Ichikawa M, Johns TG, Adelmass M, Bernard CCA. Antibody response in Lewis rats injected with myelin oligodendrocyte glycoprotein derived peptides. Int Immunol 1996; 8: 1667-1674.

13. Ichikawa M, Johns TG, Liu J, Bernard CCA. Analysis of the fine B cell specificity during the chronic/relapsing course of a multiple sclerosis-like disease in Lewis rats injected with the encephalitogenic myelin oligodendrocyte glycoprotein peptide 35-55. J Immunol 1996; 157: 919-926.

14. Jaśkiewicz E. Epitopy na białkach mieliny rozpoznawane przez autoprzeciwciała obecne $u$ chorych na stwardnienie rozsiane. Postepy Hig Med Dosw 2004; 58: 472-482.

15. Juryńczyk M, Walczak A, Jurewicz A, Jesionek-Kupnicka D, Szczepanik M, Selmaj K. Immune Regulation of Multiple Sclerosis by Transdermally Applied Myelin Peptides. Ann Neurol 2010; 68: 593-601.

16. Kawakami N, Bartholomäus I, Pesic M, Mues M. An autoimmunity odyssey: how autoreactive T cells infiltrate into the CNS. Immunol Rev 2012; 248: 140-155.

17. Kelly KA, Whitacre CC. Oral tolerance in EAE: reversal of tolerance by T helper cell cytokines. J Neuroimmunol 1996; 66: 77-84.

18. Kurzepa K, Kasarełło K, Baranowska B, Grabowska A, Walisiewicz-Niedbalska W, Różycki K, Kwiatkowska-Patzer B, Lipkowski AW. Wykorzystanie odpadowego wieprzowego rdzenia kręgowego jako cennego źródła substancji aktywnych biologicznie. Polimery 2012; 57: 29-33.

19. Kwiatkowska-Patzer B, Baranowska B, Walski M, Lipkowski AW. Influence of spinal cord protein hydrolysate upon the blood brain barrier changes due to experimental allergic encephalomyelitis in Lewis rats. Ultrastructural study. Folia Neuropathol 2003; 41: 29-34.

20. Kwiatkowska-Patzer B, Michalkiewicz J, Kubiszewska I, Zielińska J, Kasarello K, Kurzepa K, Lipkowski AW. Spinal cord hydrolysate ameliorate immunological reaction in experimental allergic encephalomyelitis. Acta Neurobiol Exp (Warsz) 2009; 69: 73-78.

21. Kwiatkowska-Patzer B, Walski M, Frontczak-Baniewiecz M, Zalewska T, Baranowska B, Lipkowski AW. Matrix metalloproteinases activity and ultrastructural changes in the early phase of experimental allergic encephalomyelitis. The effect of oral treatment with spinal cord hydrolysate proteins in Lewis rat. The pilot study. Folia Neuropathol 2004; 42: 107-111.

22. Lider O, Santos LMB, Lee CSL, Higgins PJ, Weiner HL. Supression of Experimantal Autoimmune Encephalomyelitis by Oral Administration of Myelin Basic Protein. II. Suppression of Disease and in Vitro Immune Responses Is Mediated by Antigen Specific CD8+ T Lymphocytes. J Immunol 1989; 142: 748-752.

23. Link H., Xiao BG. Rat models as tool to develop new immunotherapies. Immunol Rev 2001; 184: 117-128.

24. Lipkowski AW, Baranowska B, Marczak E, Kwiatkowska-Patzer B, Gajkowska B, Walski M. Protein hydrolysates for oral tolerance. Biofactors 2000; 12: 147-150.

25. Ljubisavljevic S, Stojanovicl, Pavlovic D, Milojkovic M, SokolovicD, Stevanovic I, Petrovic A. Suppression of the lipid peroxidation process in the CNS reduces neurological expression of experimentally induced autoimmune encephalomyelitis. Folia Neuropathol 2013; 51: 51-57.

26. Meyer AL, Benson JM, Giennap IE, Cox KL, Whitacre CC. Supression of murine chronic relapsing experimental autoimmune 
encephalomyelitis by the oral administration of myelin basic protein. J Immunol 1996; 157: 4230-4238.

27. Milligan NM, Newcombe R, Compston DAS. A double-blind controlled trial of high dose methylprednisolone in patients with multiple sclerosis: 1. Clinical effects. J Neurol Neurosurg Psychiatry 1987; 50: 511-516.

28. O'Gorman C, Lucas R, Taylor B. Environmental risk factors for multiple sclerosis: a review with a focus on molecular mechanisms. Int J Mol Sci 2012; 13: 11718-11752.

29. Peron JPS, Yang K, Chen M, Brandao WN, Basso AS, Commodaro AG, Weiner HL, Rzzo LV. Oral tolerance reduces Th17 cells as well as the overall inflammation in the central nervous system of EAE mice. J Neuroimmunol 2010; 227: 10-17.

30. Pierson E, Simmons SB, Castelli L, Goverman JM. Mechanisms regulating regional localization of inflammation during CNS autoimmunity. Immunol Rev 2012; 248: 205-215.

31. Pré du MF, Samson JN. Adaptive T-cell responses regulating oral tolerance to protein antigen. Allergy 2011; 66: 478-490.

32. Sellebjerg F, Frederiksen JL, Nielsen PM, Olesen J. Double-blind, randomized, placebo-controlled study of oral, high-dose methylprednisolone in attacks of MS. Neurology 1998; 51: 529-534.

33. Selmaj K. Stwardnienie rozsiane - kryteria diagnostyczne i naturalny przebieg choroby. Polski Przegląd Neurologiczny 2005; 1: 99-105.

34. Seven A, Aslan M, Incir S, Altintas A. Evaluation of oxidative and nitrosative stress in relapsing remitting multiple sclerosis: effect of corticosteroid therapy. Folia Neuropathol 2013; 51: 58-64.

35. Sospedra M, Martin R. Immunology of multiple sclerosis. Annu Rev Immunol 2005; 23: 683-747.

36. Sun J, Rask C, Olsson T, Holmgren J, Czerkinsky C. Treatment of experimental autoimmune encephalomyelitis by feeding myelin basic protein conjugated to cholera toxin B subunit. Proceedings of the National Academy of Sciences 1996; 93 : 7196-7201.

37. Vergelli M. Myelin Antigen autoreactivity in multiple sclerosis. Topics in Neuroscience 1999; 170-184.

38. Walczak A, Siger M, Ciach A, Szczepanik M, Selmaj K. Transdermal Application of Myelin Peptides in Multiple Sclerosis Treatment. JAMA Neurol 2013; 70: 1105-1109.

39. Wang X, Sherman A, Liao G, Leong KW, Daniell H, Terhorst C, Herzog RW. Mechanism of oral tolerance induction to therapeutic proteins. Adv Drug Deliv Rev 2013; 65: 759-773.

40. Wardrop RM, Whitacre CC. Oral tolerance in the treatment of inflammatory autoimmune diseases. Inflamm Res 1999; 48: 106-119.

41. Weiner HL. Oral tolerance: immune mechanisms and treatment of autoimmune diseases. Immunol Today 1997; 18: 335-343.

42. Weiner HL, Selkoe DJ. Inflammation and therapeutic vaccination in CNS diseases. Nature 2002; 420: 879-884.

43. Wekerle H, Kurschus FC. Animal models of multiple sclerosis. Drug Discovery Today: Disease Models 2006; 3: 359-367.

44. Wells JM, Rossi O, Meijerink M, Baarlen van P. Epithelial crosstalk at the microbiota-mucosal interface. Proc Natl Acad Sc U S A 2011; 108: 4607-4614. 